\title{
研究論女
}

\section{Research of Radioisotope Production with Fast Neutrons, (III) Preparation of ${ }^{64} \mathrm{Cu}$ of high specific activity}

\author{
速中性子による放射性同位体製造の研究，(II) \\ 高比故射能 ${ }^{64} \mathrm{Cu}$ の製造研究
}

By Chizuko SHIKATA* and Eiji SHIKATA*

\begin{abstract}
Preparation of ${ }^{64} \mathrm{Cu}$ of high specific activity by the reaction ${ }^{64} \mathrm{Zn}(n, p){ }^{64} \mathrm{Cu}$ was investigated. Five grams of zinc oxide were irradiated in JRR-1 reactor for $5 \mathrm{hr} .{ }^{64} \mathrm{Cu}$ produced was separated from zinc by an anion exchange or the combination of organic co-precipitation and anion exchange. About $1 \mathrm{mc}$ of ${ }^{64} \mathrm{Cu}$ with specific activity of more than $2.5 \times 10^{6} \mathrm{mc} / \mathrm{g} \mathrm{Cu}$ at best was prepared.

The use of an orgnic co-precipitation was useful to reduce processing time.

Some comparisons were made to a Szilard Chalmers process, which was the other method to prepare ${ }^{64} \mathrm{Cu}$ of high specific activity.
\end{abstract}

\section{INTRODUCTION}

${ }^{64} \mathrm{Cu}$ is one of the useful radioisotopes in the fields of medicine and biology. It is produced usually by the neutron irradiation of metallic copper. The specific activity of ${ }^{64} \mathrm{Cu}$ thus produced, however, being several hundreds $\mathrm{mc} / \mathrm{g}$ of copper at best, is insufficient to be applied to a human body by the toxicity of copper. By this reason ${ }^{64} \mathrm{Cu}$ of higher specific activity has been required in many cases. To fulfil these requirements, a Szilard Chalmers process was applied to prepare ${ }^{64} \mathrm{Cu}$ of higher specific activity ${ }^{(1)}$. This method is used in practice in $\mathrm{CEA}$ and ${ }^{64} \mathrm{Cu}$ from 20 to $50 \mathrm{mc} / \mathrm{mg} \mathrm{Cu}$ is supplied ${ }^{(2)}$.

Although a Szilard Chalmers process is a useful method to prepare a radioisotope of high specific activity, it has a difficulty of decomposition of the target material by radiation and temperature elevation in a reactor. As the other method of producing ${ }^{64} \mathrm{Cu}$ of high specific activity, a $(n, p)$ reaction on zinc is considerered, that is ${ }^{64} \mathrm{Zn}(n, p){ }^{64} \mathrm{Cu}$.

Metallic zinc or zinc oxide is suitable as the target material for this reaction, because they are stable towards radiation and temperature elevation in a reactor. If the copper content in the target material or reagent used in the separation procedure is sufficiently small, ${ }^{64} \mathrm{Cu}$ of very high specific activity is expected to be obtained by this method.

There are two difficulties in the use of the $(n, p)$ reaction. One difficulty is that, the reaction takes place with fast neutrons, and the number of neutrons available to this reaction is much less than that of the thermal neutrons which contributes to the $(n, \gamma)$ reaction. Moreover the activation cross section is also much less in the $(n, p)$ reaction than in the $(n, \gamma)$ reaction. So the yield of ${ }^{64} \mathrm{Cu}$ by the $(n, p)$ reaction is much less than that by the $(n, \gamma)$ reaction. The other difficulty is the formation of ${ }^{67} \mathrm{Cu}$ by the reaction ${ }^{67} \mathrm{Zn}$ $(n, p){ }^{67} \mathrm{Cu}$. Data related to the $(n, p)$ reaction on zinc are shown in Table 1 together with data of the $(n, y)$ reaction.

When radioisotopes are produced by ( $n$, $p)$ reactions, it is required to separate radio-

* 四方千鶴子, 四方英治。Japan Atomic Energy Res. Inst（日本原子力呼究所） 
Table 1 Data related to the neutron irradiation of zinc

\begin{tabular}{|c|c|c|c|c|c|c|c|}
\hline $\mathrm{Zn}$ isotope & $\begin{array}{c}\text { Abundance } \\
(\%)\end{array}$ & Reaction & Produced RI & Half-life & $\begin{array}{l}\text { Cross- } \\
\text { section } \uparrow\end{array}$ & $E_{T}(\mathrm{MeV})$ & $E_{\mathrm{eff}}(\mathrm{MeV})$ \\
\hline${ }^{64} \mathrm{Zn}$ & 48.89 & $\begin{array}{ll}n, & p \\
n, & \gamma\end{array}$ & ${ }^{84} \mathrm{Cu}$ & $\begin{array}{l}12.8 \mathrm{hr} \\
245 \mathrm{~d}\end{array}$ & $\begin{array}{r}39 \mathrm{mb} \\
0.4 \mathrm{~b}\end{array}$ & $\begin{array}{c}-0.21 \\
-\end{array}$ & $\begin{array}{l}4.8 \\
-\end{array}$ \\
\hline${ }^{66} \mathrm{Zn}$ & 27.81 & $n, p$ & ${ }^{66} \mathrm{Cu}$ & $5.15 \mathrm{~m}$ & - & $\therefore$ & - \\
\hline${ }^{87} \mathrm{Zn}$ & 4. 11 & $n, p$ & ${ }^{87} \mathrm{Cu}$ & $59 \mathrm{hr}$ & $0.64 \mathrm{mb}$ & -0.21 & 4.8 \\
\hline${ }^{68} \mathrm{Zn}$ & 18.56 & $n, \gamma$ & $\begin{array}{l}{ }^{68 m} \mathrm{Zn} \\
{ }^{60} \mathrm{Zn}\end{array}$ & $\begin{array}{l}13.8 \mathrm{hr} \\
52 \mathrm{~m}\end{array}$ & $\begin{array}{l}0.097 \mathrm{~b} \\
1.0 \mathrm{~b}\end{array}$ & - & - \\
\hline
\end{tabular}

$\dagger$ The values of cross sections are for thermal neutrons in the case of the $(n, \gamma)$ seactions and for fission neutrons in the case of the $(n, p)$ reactions.

isotopes in carrier-free or in extremely small amount from the bulk of target material. Although an ion exchange method is one of the useful methods in such a case, it has a diffculty of taking long time, when large amount of a target material is processed. If it is possible to separate a radioisotope in question roughly from the target material before an ion exchange method, the processing time is considerably reduced. A method has been reported ${ }^{(3)}$ to concentrate effectively a substance in small quantity, in which the substance is co-precipitated with the precipi-

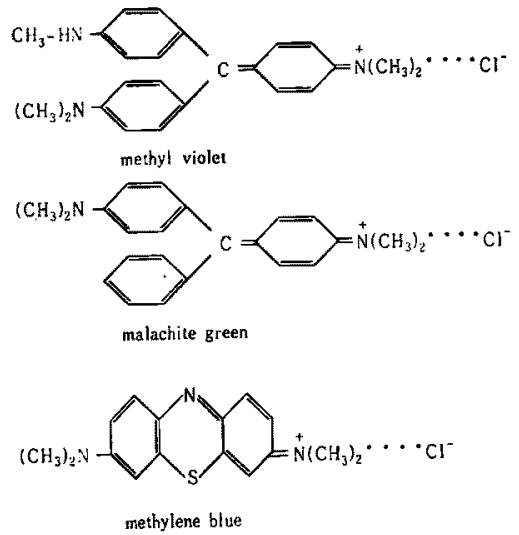

ta te of methyl violet-iodide or thiocyanate. In the case of zinc-copper separation, for example, ammonium iodide and methyl violet solutions are added successively to the solution of zinc containing small amount of copper under violent stir. Copper ion forms a complex anion with iodide ion and it is co-precipitated with methyl violet-iodide precipitate forming insoluble salt with methyl violet cation. Besides methyl violet, crystal violet, methylene blue, malachite green and rhodamine $B$, which have the same radical as shown in Fig. 1, are also applicable in the same way.

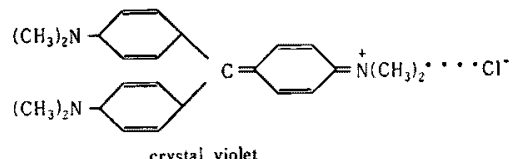

crystal violet

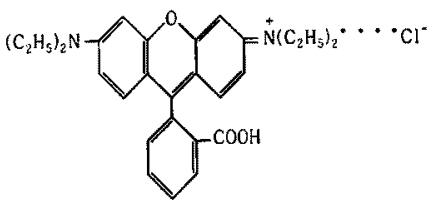

rhodamine B

Fig. 1. Organic co-precipitants

In this report two points were investigated in regard to the preparation of ${ }^{64} \mathrm{Cu}$ of high specific activity in JRR-1 reactor.

One is the investigation of the usefulness of the $(n, p)$ reaction against the Szilard Chalmers process, and the other is applicability of the "organic co-precipitant" to reduce processing time.

\section{Experiments and Results}

\section{Target material and irradiation}

Zinc oxide, a guaranteed reagent supplied by Kanto Chemicals Co., was used as a tar- 
get material. It was irradiated for $5 \mathrm{hr}$ in No. 1 experimental hole of JRR-1, which run through the center of the core, in No. 2 experimental hole of JRR-1, which run tangentially to the core and for $20 \mathrm{~min}$ in a pneumatic tube of JRR-2. The thermal neutron fluxes of these holes were $0.96 \times 10^{12}, 5.4 \times 10^{11}$ and $5 \times 10^{12} \mathrm{n} / \mathrm{cm}^{2} / \mathrm{sec}$ respectively.

\section{General procedures}

(1) Ion exchange separation

An anion exchange separation ${ }^{(4)}$ was used. Five grams of irradiated zinc oxide were dissolved in $6 \mathrm{~N}$ hydrochloric acid to give 100 $\mathrm{m} l$ solution $4 \mathrm{~N}$ in hydrochloric acid. Whole the solution or an aliquot of it was added to a column of Diaion SA-100, from 100 to 200 mesh, which had been washed previously with $4 \mathrm{~N}$ hydrochloric acid. The column was washed with $4 \mathrm{~N}$ hydrochloric acid. ${ }^{64} \mathrm{Cu}$ adsorbed on the column was eluted with $0.5 \mathrm{~N}$ hydrochloric acid. Volume of sample solution, amount of zinc contained in it, and dimensions of column are shown in Table 2. The separation of ${ }^{64} \mathrm{Cu}$ from zinc was complete. An example of the elution curve is shown in Fig. 2.

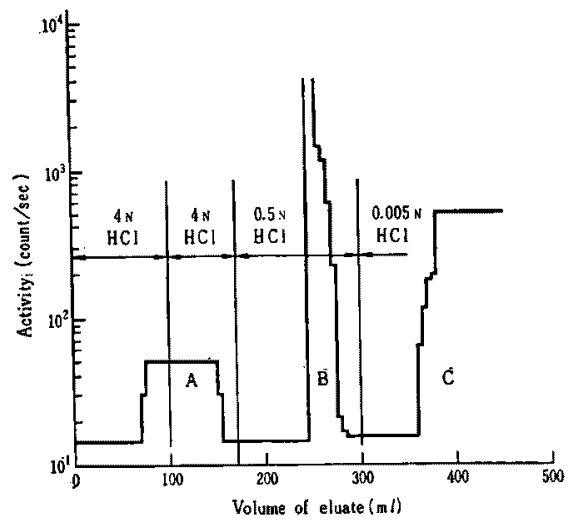

Sample solution: $100 \mathrm{ml}$ of $4 \mathrm{~N} \mathrm{HCl}$ which contained zinc, $5 \mathrm{~g}$ as $\mathrm{ZnO}$

Column: Diaion SA-100, $2.5 \mathrm{~cm}$ in diameter and $35 \mathrm{~cm}$ in length

Washing: $4 \mathrm{~N} \mathrm{HCl}, 70 \mathrm{ml}$

Eluent: $0.5 \mathrm{~N} \mathrm{HCl}$ for ${ }^{64} \mathrm{Cu}$ and $0.005 \mathrm{~N} \mathrm{HCl}$ for zinc

Flow rate: $0.6 \mathrm{~m} / / \mathrm{min}$ throughout the experiment

Fraction A: ${ }^{24} \mathrm{Na}, \mathrm{B}:{ }^{61} \mathrm{Cu}, \mathrm{C}: \mathrm{Zn}^{*}$

Fig. 2 Elution curve for ${ }^{64} \mathrm{Cu}$ and zinc
Table 2 Conditions of ion exchange separation

\begin{tabular}{c|c|c|c|c}
\hline $\begin{array}{c}\text { Volume of } \\
\text { Zn solution } \\
(\mathrm{m} l)\end{array}$ & $\begin{array}{c}\text { Amount } \\
\text { of } \mathrm{Zn} \\
(\mathrm{g})\end{array}$ & \multicolumn{2}{|c|}{ Column } & Flow rate \\
$(\mathrm{cm})$ & $\begin{array}{c}\text { length } \\
(\mathrm{cm})\end{array}$ & $(\mathrm{m} / \mathrm{min})$ \\
\hline $5, \begin{array}{c}\text { decompos- } \\
\text { ed ppt }\end{array}$ & $\begin{array}{c}\text { up to } \\
0.1\end{array}$ & 1 & 8 & 0.6 \\
$18 \sim 20$ & $0.4 \sim 1$ & 1.3 & 20 & 0.6 \\
100 & 5 & 2.5 & 35 & 0.6 \\
\hline
\end{tabular}

(2) Co-precipitation of ${ }^{64} \mathrm{Cu}$ with an organic co-precipitant

Zinc oxide was dissolved in hydrochloric acid to give $100 \mathrm{~m} l$ of solution $0.1 \mathrm{~N}$ in hydrochloric acid. Ammonium iodide and an organic co-precipitant were added to the solution successively under the violent stir. The precipitate was centrifuged, washed with $2 \%$ solution of ammonium iodide and centrifuged again.

In the experiments of the recovery of ${ }^{64} \mathrm{Cu}$ and the co-precipitation of zinc, radioactivities of ${ }^{64} \mathrm{Cu}$ and zinc were counted by placing a centrifuging tube directly on a scintillation crystal.

In the experiments of the ${ }^{64} \mathrm{Cu}$ preparation, on the other hand, the precipitate was taken into perchloric acid and decomposed, After the evaporation of the resulting solution to dryness, the residue was dissolved in $4 \mathrm{~N}$ hydrochloric acid and treated with an anion exchange method described above.

(3) Determination of recovery

A known amount of copper carrier was added to an aliquot of the solution before the separation and to an aliquot of the ${ }^{64} \mathrm{Cu}$ solution prepared. Copper was precipitated as thiocyanate by the addition of sodium hydrogen sulfite and ammonium thiocyanate solution. The precipitation was centrifuged after $2 \mathrm{hr}$, washed, transfered to a glass planchet, which had been weighed, dried at $110^{\circ} \mathrm{C}$, and weighed. The recovery of ${ }^{64} \mathrm{Cu}$ was calculated from weight and radioactivity of the precipitation.

(4) Determination of ${ }^{64} \mathrm{Cu}$ yield and specific activity

The ${ }^{64} \mathrm{Cu}$ yield was measured with a $\gamma$ ray spectrometer provided with a well type 
scintillation crystal, which had been calibrated against annihilation radiation.

The amount of copper in the ${ }^{64} \mathrm{Cu}$ solution prepared was determined colorimetrically with sodium diethyldithiocarbamate ${ }^{(5)}$. Specific activity was calculated from the yield of ${ }^{64} \mathrm{Cu}$ and the copper content.

(5) Identification and investigation of purity

The radioactivity obtained was identified to be that of ${ }^{\varepsilon 4} \mathrm{Cu}$ by paperchromatography, $\gamma$ ray spectrometry, and observation of radioactive decay.

In the paperchromatographic experiments, the samples from the solution of irradiated zinc oxide, ${ }^{64} \mathrm{Cu}$ fraction and zinc fraction in Fig. 2 were developed with methanol-hydrochloric acid mixture $(10: 3)$. The paperchromatograms are shown in Fig. $3 .{ }^{64} \mathrm{Cu}$ and zinc were separated completely, and their $R_{f}$ values, 0.7 and 0.9 respectively, agreed with those of the literature ${ }^{(6)}, 0.7$ and 0.9 respectively.

$\gamma$ ray spectrum was taken with the same $\gamma$ ray spectrometer as above, but not inserting a sample into the well. The spectra of the same samples as in the paperchromatography are shown in Figs. 4, 5 and 6 . In the spectra of irradiated zinc and zinc fraction a photopeak due to ${ }^{65} \mathrm{Zn}(1.11 \mathrm{MeV})$ and a photo-

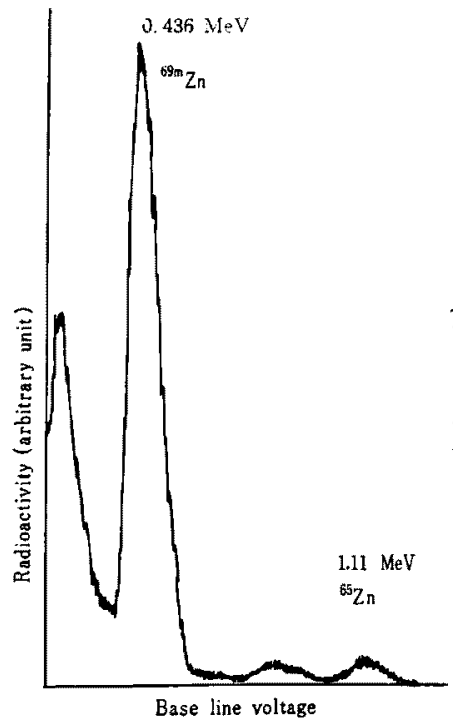

Fig. $4 \gamma$ ray spectrum of irradiated zinc

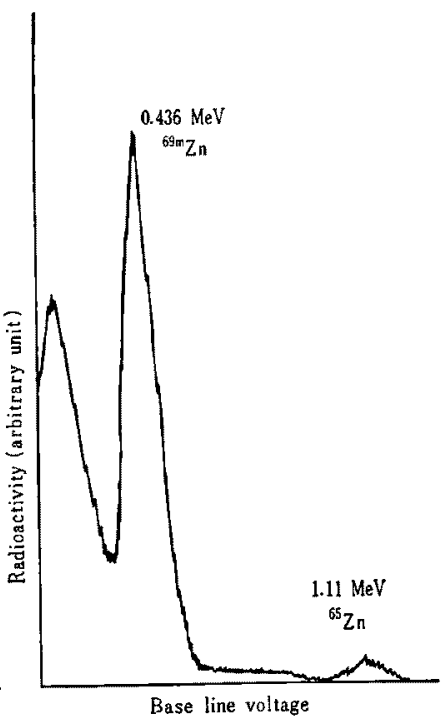

Fig. $5 \gamma$ ray spectrum of zinc fraction

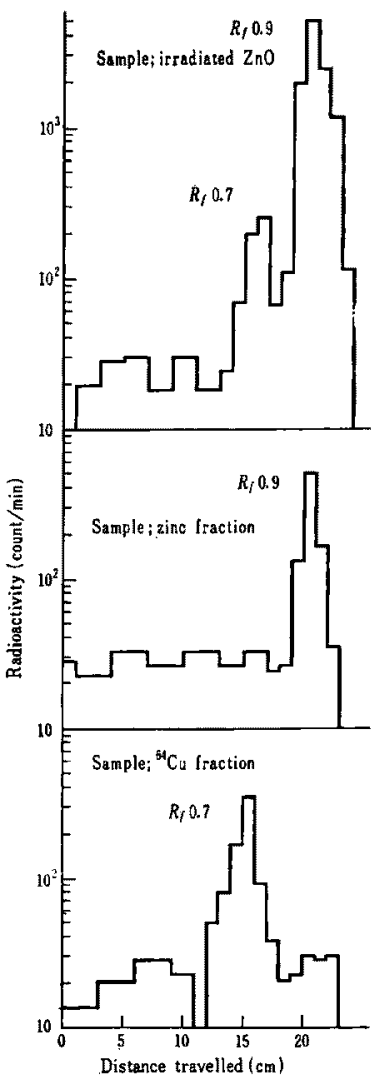

Fig. 3 Paper chromatograms of ${ }^{64} \mathrm{Cu}$ and zinc

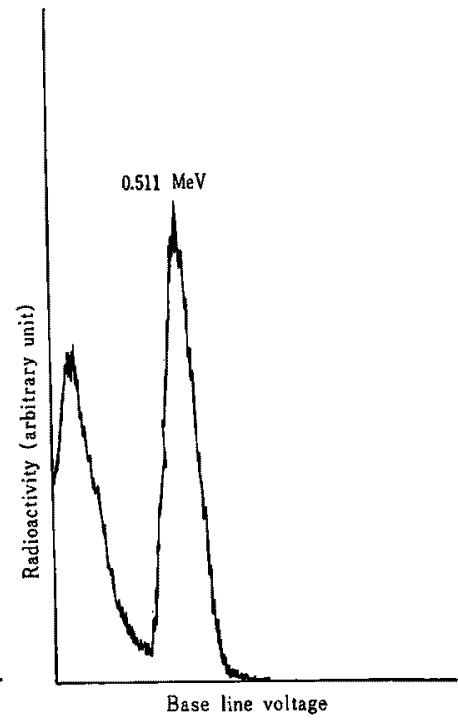

Fig. $6 \gamma$ ray spectrum of ${ }^{64} \mathrm{Cu}$ fraction 
peak due to ${ }^{69 \mathrm{~m}} \mathrm{Zn}(0.436 \mathrm{MeV})$ were recognized. In the spectrum of ${ }^{64} \mathrm{Cu}$ fraction only a photopeak of $0.511 \mathrm{MeV}$, which corresponded to annihilation radiation, was recognized.

Radioactive decay was observed with a $2 \pi$ gas-flow counter. A decay curve is shown in Fig. 7. It showed two components, one of which was recognized to be ${ }^{64} \mathrm{Cu}$ and the other to be ${ }^{67} \mathrm{Cu}$. The latterr activity was estimated from the decay and is showed in Table 5 as a ratio to the activity of ${ }^{64} \mathrm{Cu}$.

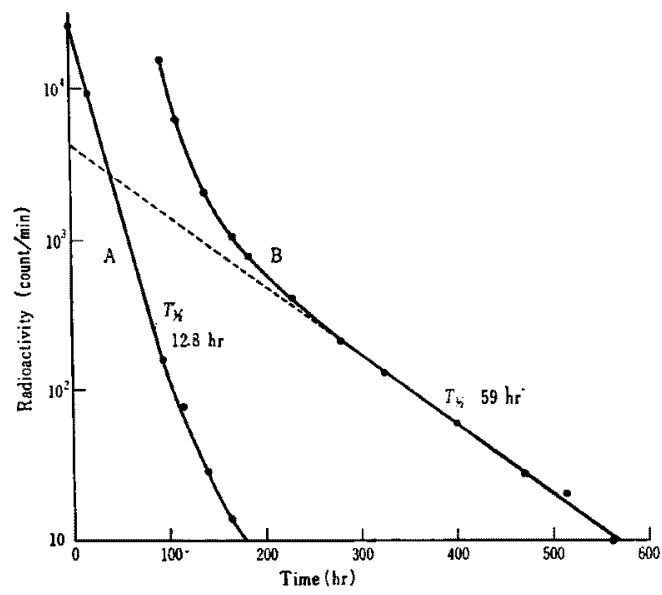

Curve $B$ was observed of the sample 100 times as concentrated as the sample $A$.

Fig. 7 Decay of ${ }^{64} \mathrm{Cu}$ prepared

(6) Determination of ${ }^{64} \mathrm{Cu}$ yield by the $(n, \gamma)$ reaction

To investigate the contribution of the $(n, \gamma)$ reaction to the production of ${ }^{64} \mathrm{Cu}$ and to compare the specific activities produced by both reactions, a small piece of copper metal was irradiated simultaneously with zinc oxide. The irradiated metal was dissolved in nitric acid and diluted. An aliquot was counted in the same way as before. The results are shown in Table 5 .

\section{Determination of copper in the organic co-precipitants}

As it was found spectrographycally that methyl violet and methylene blue contained copper, the content of copper in the organic co-precipitants was determined colorimetrically. From 0.1 to $0.2 \mathrm{~g}$ of sample were decomposed with perchloric acid and resulting solution was evaporated to dryness. The residue was dis- solved in $0.1 \mathrm{~N}$ hydrochloric acid and diluted to $25 \mathrm{ml}$. An aliquot was taken for analysis. The results are shown in Table 3.

Table 3 Copper content in the organic co-precipitants

\begin{tabular}{l|l|c}
\hline \multicolumn{1}{c|}{ Co-precipitant } & Supplier & $\begin{array}{c}\text { Cu content } \\
(\mu \mathrm{g} / \mathrm{g})\end{array}$ \\
\hline methyl violet & Kanto Chem. & 460 \\
methylene blue & Kanto Chem. & 370 \\
methylene blue & Koso Chem. & 330 \\
methylene blue & Chroma & 110 \\
crystal violet & Wako Chem. & $<2.5$ \\
malachite green & Wako Chem. & $<2.5$ \\
rhodamine B & Wako Chem. & $<2.5$ \\
\hline
\end{tabular}

\section{Co-precipitation of ${ }^{4} \mathrm{Cu}$ with the} organic co-precipitant

Conditions, such as the amount of ammonium iodide, co-precipitant and zinc, which might affect the co-precipitation was investigated.

(1) Rhodamine B and malachite green

Although these co-precipitants showed a fairly good recovery in preliminary experiments, they were not investigated for further details, because decomposition of malachite green precipitate was not easy and the precipitate of rhodamine B was hardly centrifuged.

(2) Methyl violet

The effects of the amount of ammonium iodide, co-precipitant and zinc are shown in Fig. 8.

(3) Methylene blue

The effects of the amounts of ammonium iodide and methylene blue are shown in Fig. 9, and the effects of the amount of zinc are shown in Fig. 10.

(4) Crystal violet

The effects of the amounts of ammonium iodide and crystal violet are shown in Fig. 11 and the effects of the amount of zinc are shown in Fig. 12. The effects of zinc were also investigated in the presence of copper carrier. The results are shown in Fig. 12.

(5) Co-precipitation of zinc

The amount of zinc in an arganic precipitate was determined by labeling the zinc solution with ${ }^{65} \mathrm{Zn}$ and counting the precipitation. The conditions of the experiments were chosen, under which ${ }^{64} \mathrm{Cu}$ would be co-precip- 


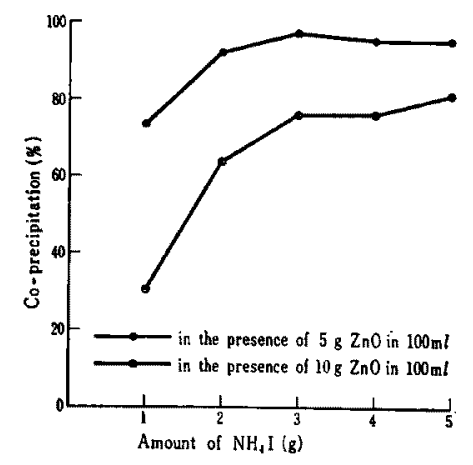

Fig. 8 Effect of the amount of $\mathrm{NH}_{4} \mathrm{I}$ on the co-precipitation with methyl violet

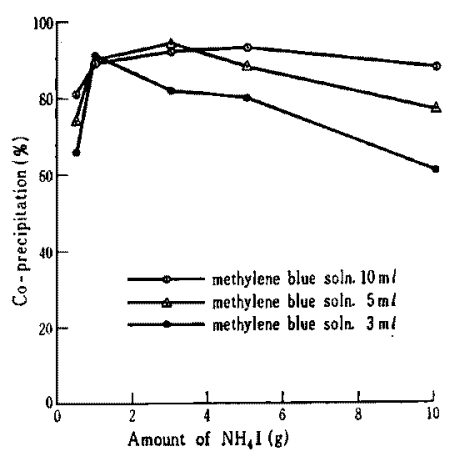

Fig. 9 Effect of the amount of $\mathrm{NH}_{4} \mathrm{I}$ on the co-precipitation with methylene blue

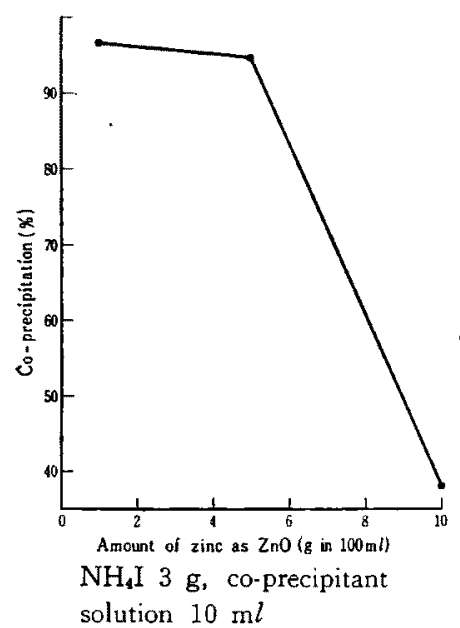

Fig. 10 Effect of zinc on the co-precipitation with methylene blue

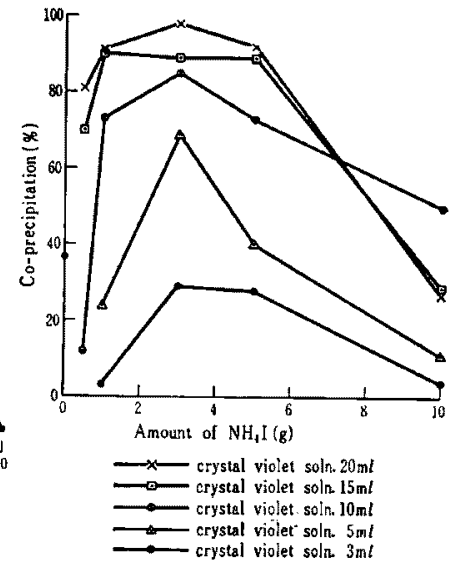

Fig. 11 Effect of the amount of $\mathrm{NH}_{4} \mathrm{I}$ on the coprecipitation with crystal violet

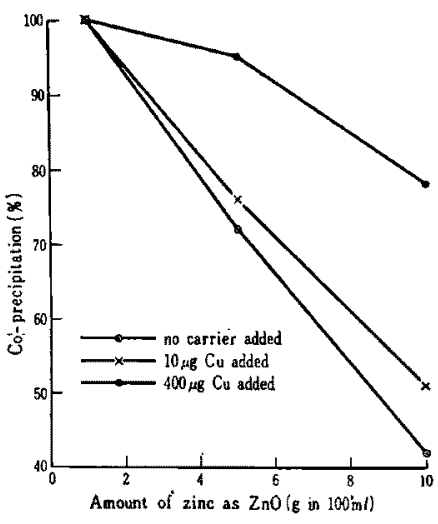

$\mathrm{NH}_{4} \mathrm{I} 3 \mathrm{~g}$, co-precipitant solution $20 \mathrm{~m} l$

Fig. 12 Effect of zinc on the co-precipitation with crystal violet itated with a good recovery. The results are shown in Table 4.

Table 4 Conditions of co-precipitation and the amounts of zinc co-precipitated

\begin{tabular}{|c|c|c|c|c|c|}
\hline & \multirow{2}{*}{$\begin{array}{l}\text { Condition } \\
\text { co-preci- } \\
\text { pitant } \\
(\mathrm{m} l)\end{array}$} & \multirow{2}{*}{$\begin{array}{l}\mathrm{NH}_{4} \mathrm{I} \\
(\mathrm{g})\end{array}$} & \multicolumn{3}{|c|}{$\mathrm{ZnO} \mathrm{g}$ in $100 \mathrm{ml}$} \\
\hline & & & 1 & 5 & 10 \\
\hline $\begin{array}{l}\text { methyl } \\
\text { violet }\end{array}$ & 10 & 1 & $\left|\begin{array}{ll}\% & 1.6 \\
m & 16\end{array}\right|$ & 100 & $230^{2.3}$ \\
\hline $\begin{array}{l}\text { methylene } \\
\text { blue }\end{array}$ & 10 & 1 & $\left|\begin{array}{ll}\% & 0.9 \\
\mathrm{mg} & 9\end{array}\right|$ & 100 & $190^{1.9}$ \\
\hline $\begin{array}{l}\text { crystal } \\
\text { violet }\end{array}$ & 20 & 3 & $\begin{array}{ll}\% & 0.7 \\
\mathrm{mg} & 7.0\end{array} \mid$ & $\begin{array}{r}0.4 \\
21.5\end{array}$ & $\begin{array}{r}0.6 \\
56.0\end{array}$ \\
\hline
\end{tabular}

(6) Conclusion of the organic co-precipitation method

Although methyl violet and methylene blue showed higher recovery than crystal violet, they were not suitable for the preparation of ${ }^{64} \mathrm{Cu}$ of high specific activity because of their copper content.

Generally the more co-precipitant showed the higher recovery, but resulted in the more precipitation, and it was not desirable for the latter processing.

With the increase of the amount of ammonium iodide the co-precipitation of ${ }^{64} \mathrm{Cu}$ increased to a maximum value, over which it decreased with further increase of ammonium iodide. This tendency was remarkable in the experiments with crystal violet.

The presence of zinc also affected the co-precipitation of ${ }^{64} \mathrm{Cu}$. The co-precipitation decreased with increasing amount of zinc. It 
was also remarkable in the experiments of crystal violet. The effect could be somewhat reduced by the addition of copper carrier.

The larger effect of the amount of ammonium iodide and zinc on the co-precipitation with crystal violet might be attributable to its least content of copper.

\section{Preparation of ${ }^{64} \mathrm{Cu}$ by the combined method}

${ }^{64} \mathrm{Cu}$ was prepared from $5 \mathrm{~g}$ of irradiated zinc oxide by the combined method of an organic co-precipitation and an anion exchange, based on the above results. The conditions used in an organic co-precipitation were the same as shown in Table 4.

Recovery, purity and specific activity were investigated on ${ }^{64} \mathrm{Cu}$ prepared. The results are summarized in Table 5.

Table 5 Results of the preparation of ${ }^{84} \mathrm{Cu}$

\begin{tabular}{|c|c|c|c|c|c|c|c|c|c|}
\hline $\begin{array}{l}\mathrm{ZnO} \\
(\mathrm{g}) \\
\end{array}$ & $\begin{array}{l}{ }^{64} \mathrm{Cu}^{(\mathrm{a})} \\
\mathrm{mc} / \mathrm{g} \mathrm{Zn}\end{array}$ & $\begin{array}{l}{ }^{64} \mathrm{Cu}^{(b)} \\
\mathrm{mc} / \mathrm{g} \mathrm{Cu}\end{array}$ & $\mid \begin{array}{c}\text { Recovery } \\
(\%)\end{array}$ & $\begin{array}{c}\mathrm{Cu} \\
\left(\mu_{\mathrm{g}}\right)\end{array}$ & $\begin{array}{c}\text { Spec. act. } \\
(\mathrm{mc} / \mathrm{g})\end{array}$ & $\begin{array}{c}{ }^{67} \mathrm{Cu} /{ }^{64} \mathrm{Cu} \\
(\%)\end{array}$ & $\frac{(n, p)^{(\mathbf{c})}}{(n, \gamma)}$ & Method $^{(\mathrm{d})}$ & $\operatorname{Remarks}^{(e)}$ \\
\hline 1.00 & 0.24 & 55.5 & 95 & $<0.1$ & $>2.5 \times 10^{6}$ & 0.16 & $>4.4 \times 10^{4}$ & I & No. 1 \\
\hline 1.15 & 0.24 & 43.0 & 95 & $<0.2$ & $>1.2 \times 10^{6}$ & - & $>2.8 \times 10^{4}$ & I & No. 1 \\
\hline 1.00 & 0.23 & 39.0 & 95 & $<0.2$ & $>1.2 \times 10^{6}$ & - & $>3.1 \times 10^{4}$ & I & No. 1 \\
\hline 0.40 & $5.7 \mu_{\mathrm{c}}$ & 14.6 & 95 & $<0.1$ & $>2.3 \times 10^{4}$ & - & $>1.6 \times 10^{3}$ & I & No. 2 \\
\hline 0.40 & $11 \mu_{\mathrm{C}}$ & 22.0 & 95 & $<0.1$ & $>4.4 \times 10^{4}$ & - & $>2.0 \times 10^{3}$ & I & No. 2 \\
\hline 0.50 & $6.8 \mu_{\mathrm{C}}$ & 9.8 & 95 & $<0.1$ & $>1.7 \times 10^{4}$ & - & $>1.7 \times 10^{3}$ & I & No. 2 \\
\hline 5.00 & 0.29 & 44.0 & 94 & 6.5 & $2.3 \times 10^{5}$ & 0.11 & $5.1 \times 10^{3}$ & I & No. 1 \\
\hline 5.00 & 0.29 & 43.0 & 95 & 4.5 & $3.3 \times 10^{5}$ & 0.11 & $7.5 \times 10^{3}$ & I & No. 1 \\
\hline 5.00 & 0.28 & 43.0 & 88 & 62.5 & $2.2 \times 10^{4}$ & 0.12 & $5.2 \times 10^{2}$ & MV, I & No. 1 \\
\hline 5.00 & 0.27 & 45.0 & 88 & 115 & $1.2 \times 10^{4}$ & 0.12 & $2.6 \times 10^{2}$ & MV, I & No. 1 \\
\hline 5.00 & 0.21 & - & 84 & 34.0 & $3.1 \times 10^{4}$ & 0.12 & - & $\mathrm{MB}, \mathrm{I}$ & No. 1 \\
\hline 5.00 & 0.16 & 47.0 & 70 & $<0.5$ & $>1.6 \times 10^{8}$ & 0.20 & $>3.4 \times 10^{4}$ & $\mathrm{CV}, \mathrm{I}$ & No. 1 \\
\hline 5.00 & 0.22 & 44.0 & 66 & $<0.5$ & $>2.2 \times 10^{8}$ & 0.14 & $>5.0 \times 10^{4}$ & CV, I & No. 1 \\
\hline 5.00 & $4.6 \mu_{\mathrm{c}}$ & 40.0 & 67 & 3.8 & $6.1 \times 10^{3}$ & - & 1. $5 \times 10^{2}$ & $\mathrm{CV}, \mathrm{I}$ & JRR-2 \\
\hline 5.00 & $3.7 \mu_{\mathrm{C}}$ & 35.0 & - & $<0.5$ & $>3.7 \times 10^{4}$ & - & $>1.1 \times 10^{3}$ & CV, I & JRR-2 \\
\hline
\end{tabular}

\footnotetext{
(a) Activities prepared by the $(n, p)$ reaction.

(b) Activities prepared by the $(n, \gamma)$ reaction.

(c) Ratios of the specific activities prepared by the $(n, p)$ reaction to those prepared by the $(n, \gamma)$ reaction.

(d) I: ion exchange, MV: co-precipitation with methyl violet, MB: co-precipitation with methylene blue, $\mathrm{CV}$ : co.precipitation with crystal violet

(e) No.1: No.1 experimental hole of JRR-1, No.2: No.2 experimental hole of JRR-1, JRR-2: a pneumatic tube of JRR-2

All the values of activities show the activities at $24 \mathrm{hr}$ after the shut-down of the reactor or the removal from the reactor.
}

\section{Discussion}

About $0.3 \mathrm{mc}$ of ${ }^{64} \mathrm{Cu}$ per $\mathrm{g}$ of zinc were prepared by the neutron irradiation in No. 1 hole of JRR-1 for $5 \mathrm{hr}$. As the $(n, p)$ reaction is a threshold reaction, the much increase in the yield of ${ }^{64} \mathrm{Cu}$ cannot be expected. ${ }^{67} \mathrm{Cu}$ exsists ranging from 0.1 to $0.2 \%$ of ${ }^{64} \mathrm{Cu}$. The activities of ${ }^{64} \mathrm{Cu}$ and ${ }^{67} \mathrm{Cu}$ were calculated as $0.5 \mathrm{mc}$ and $0.5 \mu \mathrm{c} / \mathrm{g}$ of zinc respectively, on the basis of the fission neutron flux in No. 1 hole, $1.3 \times 10^{12} \mathrm{n} / \mathrm{cm}^{2} / \mathrm{sec}^{(5)}$, and the cross-sections in Table 1 . They are in good agreement with experimental values, $0.3 \mathrm{mc}$ and $0.5 \mu \mathrm{c} / \mathrm{g}$ of zinc respectively.

The existence of ${ }^{67} \mathrm{Cu}$ is a disadvantage of the method against the Szilard Chalmers process, it has, on the other hand, a further possibility of the production of a copper radioisotope with a longer half-life. If zinc enriched in ${ }^{67} \mathrm{Zn}$, which contains ${ }^{67} \mathrm{Zn}$ ranging from 50 to $75 \%$, is irradiated at the same condition, ${ }^{67} \mathrm{Cu}$ ranging from 58 to $88 \mu \mathrm{c}$ will be produced per $g$ of zinc, and the ratio 
${ }^{67} \mathrm{Cu} /{ }^{64} \mathrm{Cu}$ will be still more raised.

The other disadvantage, which attributed to the smaller fast neutron flux in a reactor and to the smaller cross-section of a $(n, p)$ reaction, is easily seen by the comparing the yields of ${ }^{64} \mathrm{Cu}$ in No. 1 hole to that in No. 2 hole in Table 5 . Between 2 holes decrease of ${ }^{64} \mathrm{Cu}$ produced by the $(n, p)$ reaction is much larger than that produced by the $(n, \gamma)$ reaction. This means that with the increasing distance from the core center of the reactor the distribution of fast neutron decreases much rapidly than that of thermal neutron. Therefore the practical production of ${ }^{64} \mathrm{Cu}$ by the $(n, p)$ reaction should be subjected to the limitation of a position in a reactor.

From the viewpoint of the preparation of ${ }^{64} \mathrm{Cu}$ of high specific activity, the $(n, p)$ reaction has an advantage over the Szilard Chalmers process. Specific activity of ${ }^{64} \mathrm{Cu}$ prepared by anion exchange or crystal violet co-precipitation method, in Table 5, is more than 20 times as high as that supplied by $\mathrm{CEA}$, and 3 times as high as that reported by Payne and his co-workers, $350 \mathrm{mc} / \mathrm{mg}^{(2)}$. In these cases the neutron fluxes are almost the same order of $10^{12} \mathrm{n} / \mathrm{cm}^{2} / \mathrm{sec}$.

As a method of separation of ${ }^{64} \mathrm{Cu}$ from zinc an anion exchange method can be applied satisfactory with good purity and recovery, except it takes long time. It takes about 5 $\mathrm{hr}$ for the processing of $5 \mathrm{~g}$ of zinc oxide.

The single use of the organic co-precipitation is insufficient because it carries down a small amount of zinc. The combination of the organic co-precipitation and ion exchange method can be applied efficiently. As an organic co-precipitant crystal violet is preferential to methyl violet or methylene blue, in spite of its poorer recovery. The latter two present a better recovery, they are unsuitable for the preparation of ${ }^{64} \mathrm{Cu}$ in high specific activity by a trace amount of copper contained in them, to which, however, their good recovery might be attributed. If methyl violet or methylene blue free from copper contamination is prepared, these two co-pecipitants may be applied. By the use of the organic co-precipitation before ion exchange, the processing time is shortened to a half or below. The longest procedure in the processing is the decomposition of the organic precipitate with perchrolic acid. If ${ }^{64} \mathrm{Cu}$ and a small amount of zinc are adsorbed on an anion exchanger column directly from a solution of the organic precipitate in the mixture of toluene and hydrochloric acid-it is found the organic precipitate dissolves in the mixture -or some other solvent, the processing time can be further reduced.

The combination of the organic co-precipitation and an ion exchange or solvent extraction may be useful not only in the separation of ${ }^{64} \mathrm{Cu}$ from zinc but also in the separation of ${ }^{58} \mathrm{Co}$ from nickel, which is a case of ${ }^{58} \mathrm{Co}$ preparation by the reaction: ${ }^{58} \mathrm{Ni}(n, p){ }^{58} \mathrm{Co}$, in the separation of ${ }^{53} \mathrm{Ni}$ from copper, which is a case of ${ }^{63} \mathrm{Ni}$ preparation by the reaction: ${ }^{63} \mathrm{Cu}(n, p){ }^{63} \mathrm{Ni}$, and in other products by $(n, p)$ reactions.

Though some comparisons of the preparation of ${ }^{64} \mathrm{Cu}$ by the $(n, p)$ reaction to that by a Szilard Chalmers process has been made, it may be concluded that the preparation of ${ }^{64} \mathrm{Cu}$ by the $(n, p)$ reaction is preferential when ${ }^{64} \mathrm{Cu}$ is required in a small amount but in extremely high specific activity.

The authors acknowledge gratefully the suggestion to the organic co-precipitation method of $\mathrm{H}$. Amano at Japan Atomic Energy Research Institute.

(Received February 19, 1962)

\section{- REFERENCE-}

(1) "Radioéléments artificiels", (1960), Commissariat a l'énergie atomique, France.

(2) B. R. Payne, P. Scargill, G. B. Cook: "Radioisotopes in Scientific Research", Vol. II , 154 167 (1958), Pergamon Press, London.

(3) V. I. KUZNETSOV: ibid., 264 283.

(4) K. A. Kraus, G. E. Moore: J. Am. Chem. Soc., 74, 843 (1952).

(5) Y, KaKITA, H. AMANO: "Bunsekikagaku Koza", 10-D, 18 (1957), Kyoritsu Shuppan Co., Tokyo.

(6) Z. Tamura: ibid., 4-C, 30. 